\title{
Relationship of Biosocial Factors and Hemoglobin Genotype with Age of Menarche among School Girls in Ilorin, Nigeria
}

\author{
Adebara IO, ${ }^{1}$ Ijaiya $\mathrm{MA}^{2}$ \\ ${ }^{1}$ Dept. of Obstetrics and Gynaecology, Federal Medical Centre, Nigeria, ${ }^{2}$ Dept. of Obstetrics and Gynaecology, University of Ilorin \\ Teaching Hospital, Nigeria
}

\begin{abstract}
Aims: Menarche is an important milestone that signals the commencement of the reproductive life of the growing girl-child. The objectives of the study was to determine the age of menarche among the school girls, the relationship between age of menarche and anthropometric measurements, haemoglobin genotype, sporting activities and age of menarche of respondents' mothers.

Methods: This was a cross-sectional study carried out among selected secondary school students in Ilorin, Nigeria, between September 2008 and April 2009. Multistage and systematic random sampling techniques were used for subjects' selection.

Results: The mean menarcheal age of the respondents was $13.21 \pm 1.29$ years while their mothers' mean menarcheal age was $14.39 \pm 1.82$ years. Girls whose mothers have high level of education and of high social class attained menarche earlier than their other colleagues. The girls' height, weight and body mass index had no significant influence on the age of menarche. The mean menarcheal age of girls with haemoglobin AA (13.25years) was lower than those with haemoglobin AS (13.79years) and haemoglobin SS (14.17years). The socioeconomic class was however, the only index that was significant on multivariate analysis.
\end{abstract}

Conclusions: Girls are attaining reproductive capacity at a younger age and socioeconomic class was the most important variable that had relationship with age of menarche.

Keywords: Age at menarche, biosocial factors, hemoglobin genotype, nigeria, schoolgirls

\section{INTRODUCTION}

Puberty is the period when endocrinological and gametogenic function of the gonads have first developed to the point when reproduction is possible. ${ }^{1}$ Puberty is characterized by marked physiological and neuroendocrine changes in the reproductive system that results in secondary sexual characteristics; it is a transition period between childhood and adult life. In girls, the first event of puberty is thelarche followed by pubarche and then menarche. ${ }^{2}$ Menarche refers to the first menstruation a girl has in life. ${ }^{1,2}$ Menarche is a relatively late event in the pubertal milestone, but it is the most striking one. Menarche signifies maturity of the hypothalamo-pituitary-

\section{CORRESPONDENCE}

Dr. Munir'deen A. Ijaiya

Dept. of Obstetrics and Gynaecology

University of Ilorin Teaching Hospital,Ilorin, Nigeria

Phone: +2348033801565

Email: munirijaiya@yahoo.com 
ovarian axis, it is the end point of a complex maturation process that has being in progress for many years before the event. The initial menstruations are anovulatory in the first 12-18 months. ${ }^{2}$

Menarche is an event that is readily identified by most women. While menarche is an easily identified event in the female, early sexual maturity in the male is more subtle and difficult to be identified. The early pubertal changes in the male include an increase in the scrotal volume and penile size. ${ }^{3}$

Menarche is a reflection of the health status of a society, it signifies sexual maturity in many African societies, the age at sexual debut; the age at first pregnancy and birth. Menarche is a predictor of some later life health condition such as carcinoma of the breast, endometrial and ovarian carcinoma, and rheumatoid arthritis among others. ${ }^{4,5}$

The exact stimulus for the onset of menarche is not known but it is influenced by genetic factors, environmental factors, nutritional factors, and medical factors.

The age of menarche varies from population to population. The age at menarche in the United States of America was found to be $11.4 \pm 1.3$ for black girls and $11.5 \pm 1.3$ for white girls. Age at menarche in Italy was $12.0 \mathrm{yrs}$, while in Germany it was 13.5 yrs. $^{3}$ In Thailand it was found to be $12.5 \mathrm{yrs}^{3}$, in Mozambique age of menarche was found to be $13.91 \pm 1.29$ yrs among girls in Maputo ${ }^{6}$, while in the West African sub-region age at menarche in Ghana ${ }^{7}$ was $13.43 \pm 1.42$ and 16 years in Senegal. ${ }^{3}$

Studies done in the various zones of Nigeria revealed that at Ife in the South Western part of the country, the age of menarche was found to be $13.98 \pm 1.38$ years ${ }^{8}$, Port Harcourt in the South-South of Nigeria found age at menarche among school girls to be $13.43 \pm 2.19^{2}$ and findings from Zaria in Northern Nigeria found the age at menarche to be 14.2 years $^{4}$ while in Jos it was $13.5 \pm 1.33$ years. ${ }^{9}$ Ilorin is in the North Central zone of Nigeria $^{1}$, a study done among school girls there about 20 years ago found the age at onset of menses to be $13.7 \pm 1.1$ years. ${ }^{1}$

The age at menarche among girls with sickle cell disease in a study done in South Eastern Nigeria was $14.5 \pm 1.13$ years compared to $13.3 \pm 1.09$ years among girls that had hemoglobin genotype AA in the same area ${ }^{10}$, similar findings were observed in a large observational study in Jamaica. ${ }^{11}$

Studies on the trends in age at menarche done in many parts of the world have shown a gradual decline in the age at which girls attained menarche, countries like USA, Scandinavian countries, Chuvasha region of Russia and Nigeria. ${ }^{12}$

Assessment of age at menarche can be done by either the recall method or by the status quo method. ${ }^{3-5,13}$ The status quo method is more reliable than recall method. ${ }^{5}$ Accuracy of the information given can be influenced by peer pressure and the ability of the girls to remember details about their development. ${ }^{4}$

The aim of this study was to determine the relationship of anthropometric measurements and hemoglobin genotype with age of menarche among schoolgirls in Ilorin, Nigeria. The specific objectives of the study include determination of the age of menarche among the school girls, the relationship between age of menarche and anthropometric measurements, hemoglobin genotype, sporting activities and mother's age of menarche.

\section{METHODS}

This prospective study, a descriptive cross sectional in design was conducted among school girls in llorin, Nigeria between September 2008 and April 2009. University of Ilorin teaching hospital ethical and research committee approved the study.

Study population: The study population was selected secondary school students who had attained menarche. Inclusion criteria used are as follows: Students, who are of Nigerian nationality, must have attained menarche, can recall the age at which they attained menarche and willing to participate and has given consent. Those that are non Nigerians, have not attained menarche, could not recall the age at which they attained menarche, students who could not remember their age at menarche or students who are not willing to participate in the study were excluded.

Sample size: The calculated minimum sample size was 349; making allowance for at least $20 \%$ attrition rate, the sample size was 419 .

Sampling technique: Multi-stage sampling technique was employed in selecting the subjects for the study.

Data collection: Pretested questionnaire was administered. The following information were obtained. Students' age, level of education, menstrual history, family history, educational level of parents and parents occupation from which respondents' social class was calculated and clinical profile of the students were obtained. The recall method was used to obtain information about age at menarche. However this method is less accurate than status quo method. ${ }^{6-8,17,18}$ The students' anthropometric measurements such as weight and height were done and body mass index calculated.

Laboratory analysis: Hemoglobin genotype was determined using the electrophoretic tank with cellulose acetate paper at a ph of 8.4

Data analysis: Data entry and analysis was carried out with a micro-computer using the Epi info version 6.0 
software packages. Student T test was used to test means of continuous variables and discrete variables to test for any statistical difference with the mean age at menarche. The haemoglobin genotype and mean menarcheal age was also analyzed for any statistical significance. A p-value less than 0.05 was considered significant.

\section{RESULTS}

Five hundred and sixty students selected from five secondary schools within llorin metropolis agreed to participate in the study but only 407 students completed their questionnaires sufficiently for analysis, giving a response rate of $97.14 \%$.

The age range of the respondents was between 11 and 21 years with a mean age of $15.40 \pm 1.69$ years. Majority of the respondents $288(70.8 \%)$ were in the age range of 15 to 19 years at the time of the study with mean age of 15.4 \pm 1.69 years. Most of the respondents, 371 (91.1\%) were in senior secondary school classes (SSS 1-3). The remaining students were in the junior secondary (JSS)classes.(Table2)

\section{Menstrual history of respondents}

Table 1 illustrates the menstrual history of the respondents. The menarcheal age ranged between 9 and 17 years, the mean age at menarche of the study population was 13.21 \pm 1.29 years. Majority $(76.7 \%)$ attained menarche between the ages of 12-14 years.

\section{Table 1. Age distribution of respondents}

\begin{tabular}{lll}
\hline Age Range (years) & Number & Percentage (\%) \\
\hline $10-14$ & 112 & 27.5 \\
$15-19$ & 288 & 70.8 \\
$20-24$ & 7 & 1.7 \\
& 407 & 100 \\
\hline
\end{tabular}

Mean age $=15.4 \pm 1.69$ years

Only 161 respondents gave information on their cycle length. The cycle length of the studied population ranged between $18-60$ days, with a mean of $26.03 \pm 6.14$ days. Of this number, 15 (9.3\%) had cycle length less than 21days, $109(67.7 \%)$ had cycle length between $21-28$ days, 34 had cycle length between 29-35 days and 3 had cycle length greater than 35 days.

Parents' educational status and occupation: The educational status of parents and mean menarcheal age of respondents is as illustrated in table 2. Three hundred and forty-eight $(85.5 \%)$ of the respondents' mothers had either secondary school education or tertiary education, $59(14.5 \%)$ had either formal education or only primary school education. The mean menarcheal age of girls whose mothers had tertiary education was found to be $12.96 \pm$ 1.30 years, while those with no formal education 13.65 \pm 1.42 years. Regarding father's educational status, 369
$(90.7 \%)$ of the fathers had either secondary or tertiary education, and (9.3\%) had either no formal education or they had only primary school. The mean age at menarche was $13.06 \pm 1.32$ years in children whose father had tertiary education and those whose fathers had no formal education was $13.38 \pm 1.41$ years. (Table 4 )

The occupation of the parents ranged from the professional groups (38.3\%), non-academic professional (26.5\%) and the non-manual skilled workers (8.4\%). The other parents belong to the manual work $(24.3 \%)$ and the unemployed group (2.5\%). The children whose parents are professionals attain menarche earlier than the other groups $(p=0.0003)$.

Table 2. Distribution of respondents by level of education

\begin{tabular}{lll}
\hline $\begin{array}{l}\text { Level of } \\
\text { education }\end{array}$ & Number & Percentage (\%) \\
\hline JSS 1 & 10 & 2.5 \\
JSS 2 & 16 & 3.9 \\
JSS 3 & 10 & 2.5 \\
SSS 1 & 209 & 51.4 \\
SSS 2 & 118 & 29.0 \\
SSS 3 & 44 & 10.8 \\
Total & 407 & 100 \\
\hline
\end{tabular}

Table 3 shows the social class distribution of respondents. Respondents in social class I had the lowest mean age at menarche, which was $12.67 \pm 1.20$ years, while those in social class IV had the highest mean menarcheal age of $13.78 \pm 1.15$ years. Two hundred and twenty-two (54.6\%) of these students were from the upper socio-economic class (classes I and II); the mean menarcheal age of girls in the upper socio-economic class was $12.90 \pm 1.29$ years, this was significantly lower than the mean age at menarche of the other 185 (45.6\%) girls in the lower socio-economic class (classes III,IV and V) whose mean menarcheal age was $13.58 \pm 1.20$ years $(p=0.0000)$.

Table 3. Distribution of respondents' age at menarche

\begin{tabular}{lll}
\hline Age at menarche & Number & Percentage(\%) \\
\hline $9-11$ & 33 & 8.1 \\
$12-14$ & 312 & 76.7 \\
$15-17$ & 62 & 15.2 \\
& 407 & 100 \\
\hline
\end{tabular}

Distribution by sports activities: One hundred and sixtynine $(41.52 \%)$ in the studied population were involved in one form of sports activity or the other. The sports activities they were involved in were mainly athletics. The other sporting activities ranged from the light type such as table tennis to the more vigorous ones such as football, basketball, and volleyball. The mean age at menarche of 
respondents involved in the sport activities was 13.14 \pm 1.28 as against $13.27 \pm 1.30$ years for those that were not engaged in any form of sporting activity (T 0.8, p 0.32).

Distribution of mother's age at menarche: One hundred and twenty one students mothers remembered the age at which they attained menarche. The mothers' age at menarche ranged from 10 to 19 years with a mean of 14.39 \pm 1.82 years; this was significantly higher ( $F 8.15, p=0.005$ ) when compared with the mean menarcheal age of their own daughters $12.89 \pm 1.21$ years.

Anthropometric measurements: The height of the respondents ranged between 1.4 and $1.82 \mathrm{~m}$, the mean height was $1.58 \pm 0.06 \mathrm{~m}$. Approximately half of the respondents $(51.3 \%)$ were between 1.50 and $1.59 \mathrm{~m}$. The height was not significantly related to the mean age at menarche $(p=0.81)$.

The weight ranged between 30 and $82 \mathrm{~kg}$ with a mean of $51.33 \pm 7.85 \mathrm{~kg}$. Three hundred and thirty-eight $(83.05 \%)$ students weighed between 41 and $60 \mathrm{~kg}$. The weight was not significantly related with the mean menarcheal age of respondents $(p=0.39)$.

Respondents Body mass index (BMI) distribution is illustrated in figure 1 . Majority $(80.3 \%)$ of the respondents were in the normal BMI $\left(18.5-24.9 \mathrm{~kg} / \mathrm{m}^{2}\right)$ category, 56 $(13.8 \%)$ were underweight $\left(<18.5 \mathrm{~kg} / \mathrm{m}^{2}\right), 22(5.4 \%)$ were overweight $\left(25.0-29.9 \mathrm{~kg} / \mathrm{m}^{2}\right)$ and two $(0.5 \%)$ respondents were obese $\left(\geq 30 \mathrm{~kg} / \mathrm{m}^{2}\right)$. The mean BMI of respondents was $20.54 \pm 2.63 \mathrm{~kg} / \mathrm{m}^{2}$. The body mass index with $p$ value of 0.57 was not statistically significant.

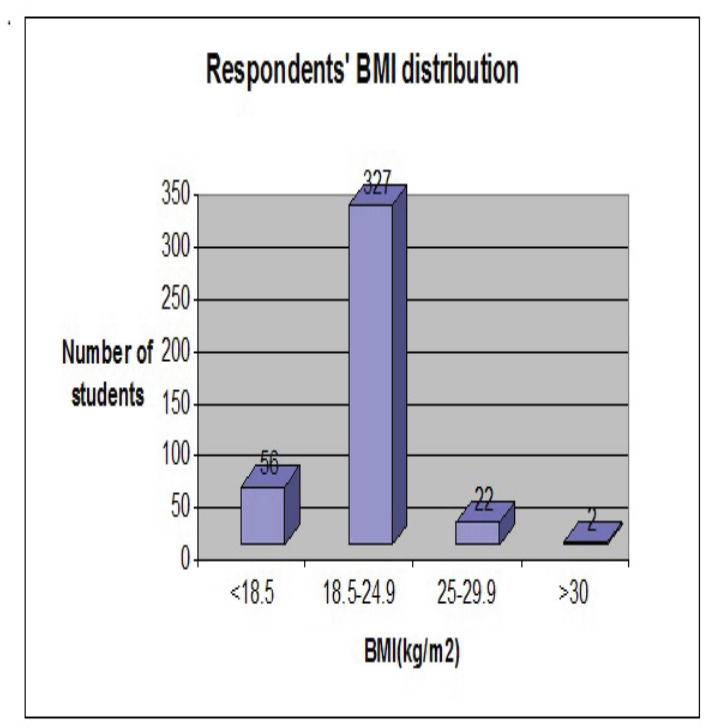

Figure 1. Bar chart showing the BMI distribution of respondents
Hemoglobin genotype: Table 4 illustrates the pattern of haemoglobin distribution and the mean menarcheal ages of respondents. Two hundred and eighty-six (70.27\%) of the students in this study had haemoglobin genotype AA, 95 (23.34\%) had haemoglobin genotype AS. Hemoglobin genotypes AC, SS and SC was found in 19 (4.67\%), six (1.47\%) and one (0.25\%) respectively. The mean menarcheal age of respondents with hemoglobin genotype AA was $13.24 \pm 1.23$ years, the respondents with haemoglobin genotypes AS, AC and SS had mean ages at menarche of $13.79 \pm 0.86$ years, $12.97 \pm 1.44$ years and $14.17 \pm 1.83$ years respectively as shown in table IV.

The age at menarche of the respondents with hemoglobin genotype SC was 12 years. The comparison of hemoglobin genotypes with mean menarcheal age was significant with $p$ value of 0.0000 . Comparison of hemoglobin genotype SC could not be done because frequency is less than five.

Table 4. Parents' educational status and mean menarcheal age of respondents

\begin{tabular}{|c|c|c|c|}
\hline $\begin{array}{l}\text { Mothers' } \\
\text { Education } \\
\text { level }\end{array}$ & $\begin{array}{c}\text { Mothers } \\
\text { Mean } \\
\text { menarcheal } \\
\text { age }\end{array}$ & $\begin{array}{c}\text { Fathers' } \\
\text { education } \\
\text { level }\end{array}$ & $\begin{array}{c}\text { Daughters' } \\
\text { Mean } \\
\text { menarcheal } \\
\text { age }\end{array}$ \\
\hline None & $13.65 \pm 1.42$ & None & $13.38 \pm 1.41$ \\
\hline $1^{0}$ education & $13.79 \pm 1.28$ & $1^{0}$ education & $14.05 \pm 1.40$ \\
\hline $2^{0}$ education & $13.35 \pm 1.18$ & $2^{0}$ education & $13.42 \pm 1.07$ \\
\hline $3^{0}$ education & $12.96 \pm 1.30$ & $3^{0}$ education & $13.06 \pm 1.32$ \\
\hline p-value & $0.0001 *$ & & $0.0012 *$ \\
\hline
\end{tabular}

A multivariate analysis to compare the mean age at menarche with various variables revealed that only the social class was significant at correlation coefficient of 0.09 and $p=0.0005$, the mother educational status had a near value of 0.056 . The other indices had a $p>0.05$.

\section{DISCUSSION}

Menarche signifies the attainment of sexual maturity in girls. ${ }^{5}$ The mean menarcheal age in this study was 13.21 \pm 1.29 years. This is comparable to the mean menarcheal age of $13.30 \pm 1.09$ years observed in Enugu in the South Eastern part of the country ${ }^{10}, 13.43 \pm 2.19$ years in Port Harcourt, South-South of Nigeria ${ }^{2}$ and $13.94 \pm 1$.31years in Ife in the south western part of Nigeria. ${ }^{14}$ However, it is less than 14.2 years found in Zaria in Northern Nigeria. ${ }^{4}$ This is also comparable to values obtained in other West Africa countries such as Ghana and Senegal. 3,7

The mean menarcheal age of this present study was noted to be less than the mean menarcheal age of $13.70 \pm$ 
1.1years found by an earlier investigator within the same environment about 25 years ago. ${ }^{1}$ This shows a decline of about 6 months in the age at which menarche was attained by girls in llorin. The decline in the age of menarche of the Nigerian girl child has been observed over the years from the earlier studies of Ellis in 1950 (14.22 \pm 1 .0years $)^{15}$, Oduntan in 1976 (13.70 \pm 0.03 years $)^{16}$, Fakeye in 1985 $(13.70 \pm 1.1 \text { years })^{1}$ and Dare in 1992 (13.98 \pm 1.30 years). ${ }^{8}$ The observed trend may be due to improved nutrition of the Nigerian girl child and the improvement in the quality of life in the urban areas of the country.

The mean menarcheal age of mothers was about 1.5 years greater than their own daughters' mean menarcheal age $(p=0.005)$. An improved quality of life over the years maybe responsible for this, some of these mothers probably attained menarche during the period of economic recession Nigeria experienced in the early-mid eighties. The lower mean menarcheal age of the daughters probably signifies the interaction of other factors other than genetics being at play in the timing of age at menarche. ${ }^{3}$ The menarcheal ages of the mothers was obtained by the recall method and this method of estimating menarcheal age has been documented to be fairly accurate in middle aged women. ${ }^{5}$

The parental education level and occupation determines the socio-economic class of the child. The age at first menstruation was found to be significantly related to the socio-economic class of the respondents $(p=0.0000)$. The school girls in the high socio-economic class attained menarche six months earlier $(p=0.0000)$ than their counterparts in the low socioeconomic class, this is in agreement with the findings of other studies. . $^{13,6-8,12,16}$ Socio-economic class has been found to be a consistent factor affecting menarche in most societies. ${ }^{3,12,16}$

Female education particularly has been found not only to improve child survival but it also improves the quality of life of the child. ${ }^{17}$ This study also found a significant difference among children whose parents are educated and those whose parents have no formal education or only have primary school education. This is in agreement with other studies. ${ }^{6,16,18}$ Education plays an important role in deciding the financial resources available to the family ${ }^{16}$ and the allocation of the resources to family upkeep, health care and quality of food available to the family Educated parents not only have better-paid jobs than their uneducated counterparts have but they also tend to have a better knowledge on nutrition.

The measured mean height and the mean weight found in this study were greater than those recorded in a previous study among schoolgirls from the same sociocultural background conducted 25 years ago. ${ }^{1}$ The higher anthropometric measurements may be a reflection of the improved socio-economic status of the studied community. This may also explain the secular trend in the age of menarche noted. The earlier study was conducted during the military era when the Structural Adjustment Program was introduced into the country in the mid eighties. The secular trend noted is in consonance with observations from other parts of the world..$^{3,12,19}$ The possible explanation for this trend is the improvement in socio-economic status of parents and the better nutritional status of schoolgirls. A similar finding of higher anthropometric measurement was observed among migrant Senegalese adolescents compared with those adolescents who reside in the rural areas; the migrant group with the higher anthropometric measurements attained menarche at an earlier age than their counterparts in the rural area. ${ }^{19}$ This is further highlighted with a significant finding of a younger age at menarche of the high social class, who have greater mean height and body mass index $(p=0.038$ and 0.047 respectively) in comparison with those in the low social class. The mean weight was however found not to be significantly different across the social classes $(p=0.59)$. The weight may be a reflection of the current nutritional status while the height may reflect the nutritional status of the individual over the years. The non significant statistical finding defers from reports of some investigators who noted either weight or height as the significant factor determining menarche. . $^{3,4}$

A critical weight of $48.5 \mathrm{~kg}$ has been proposed as being necessary for menarche to occur ${ }^{18}$, while this study did not aim to verify this, the observation from the study was that the mean weight $(51.33 \pm 7.85 \mathrm{~kg})$ of the respondents was greater than this proposed critical weight. This observation may however be due to the fact the anthropometric measurements of most of the respondents were taken many months after their menarcheal ages.

Homozygous sickle cell disease (haemoglobin genotype SS) occurred in $1.47 \%$ of this study; this is in agreement with the national prevalence of homozygous sickle cell disease in the country. ${ }^{20}$ Respondents with haemoglobin genotype SS attained menarche at a significantly higher age when compared with respondents with non-sickle cell disease haemoglobin genotypes $(p=0.0000)$. The factor responsible for this delay is not exactly known ${ }^{10,11}$ but it may be due to the common occurrences of frequent childhood illnesses and micro-infarction in the ovaries and pituitary gland in this group of children. The cellular immunity in homozygous sickle cell disease patient is impaired which predisposes them to recurrent infection and malaria and they are also prone to stunted growth. ${ }^{21}$ These may explain the reduced anthropometric measurements of these girls compared with their counterparts who do not have sickle cell anaemia.

The observation from this study was that all respondents with homozygous SCD are all from the high social class. The parents of this group of schoolgirls are probably more knowledgeable and more motivated in recognizing the features of ill health and seeking appropriate help for their wards. 
Hemoglobin genotype SC was found in only one patient, the age at menarche in this individual was 12 years, this menarcheal age was 2.17 years less than the mean menarcheal age of respondents with haemoglobin genotype SS. This is in agreement with findings of other investigators. ${ }^{11}$

A multivariate analysis to compare the mean age at menarche with indices with $p<0.05$ revealed that only the social class was significant at correlation coefficient of 0.09 and $p=0.0005$. This is in agreement with findings from studies done on the timing of age at menarche; the secular trend observed in the developed world coincided with the improvement in the socioeconomic conditions of those countries. ${ }^{3} \mathrm{~A}$ halt to this trend has been observed in the developed countries and a reduction in age of menarche observed among girls from less affluent countries coinciding with migration to more affluent societies, an improvement in the socioeconomic conditions in their home countries and possible improved nutrition in terms of quality and quantity. ${ }^{3}$

\section{REFERENCES}

1. Fakeye OO: Body and Body Components of Total Body water, Lean Mass and Fat at Menarche. TJOG. 1990;8:22-4.

2. Ofuya ZM. The Age at Menarche in Nigerian Adolescents from Two Different Socio-economic Classes. Online J Hlth Allied Scs. 2007:4:3.

3. Anne-Simone P, Grete T, Anders J, Niels ES, Jorma T, and JeanPierre B. The Timing of Normal Puberty and the Age Limits of Sexual Precocity: Variations around the World, Secular Trends, and changes after Migration. Endocrine Reviews. 2003;24(5):668-93.

4. Anekwe SC, Haggai DP, Ameh N. Anthropometric Measurements at Menarche Amongst in-school Girls and its Reproductive Health Implication. In: Health Sector Reforms and Maternal Health Oluyole 2005. Omigbodun A O, Olayemi O, Oladokun A, Ladipo O A (Eds).SOGON. 2006:297-9.

5. Cooper R. Validity of Age at Menarche Self-Reported in Adults. Epidemiol. Community Health. 2006;60(10):993-7.

6. Padez C. Age at Menarche of School girls in Maputo, Mozambique. Ann Hum Biol. 2003;30(4):487-95

7. Adadevoh SW, Agble TK, Hobbs C, Elkins TE. Menarcheal age in Ghanaian School girls. Int J Gynaecol Obstet. 1989;30(1):63-8.

8. Dare FO, Ogunniyi SO, Makinde SO. Biosocial Factors Affecting Menarche in a Mixed Nigerian Population. Central Afr J Med. 1992;38(2):77-81.

9. Wright EA. Menarche in Plateau State. West Afr J Med. 1990;9(3):204-7.

10. Modebe O. The Effect of Homozygous Sickle Cell Disease on the Age at Menarche in Nigerian Schoolgirls. Ann Hum Biol. 1987;14(2):181-185

11. Serjeant GR, Singhal A, Hamilton IR. Sickle Cell Disease and Age at Menarche in Jamaican Girls: Observations from a Cohort Study. Arch Dis Child. 2001;85(5):375-8.

\section{CONCLUSION}

The mean menarcheal age of school girls at llorin has reduced from $13.70 \pm 1.1$ years in 1990 to $13.21 \pm 1.26$ years. The variables significantly influencing the age of menarche in this study include the parental level of education, respondents' social class, and respondents' hemoglobin genotype. However, with multivariate analysis only the social class of the students is statistically significant.
12. Kalichman L, Malkim I, Livshits G, Kobyliansky E. Age at Menarche in a Chuvashian Rural Population. Ann Hum Biol. 2006;33(3):390

13. Winfred CW.Sickle cell anaemia and other sickling syndrome. In Wintrobe Clinical Hematology. John PG, John F, John NL(Eds) $11^{\text {th }}$ Ed. Lippincott Williams and Wilkins. 2003;40:212-24

14. Abioye-Kuteyi EA, Ojofeitimi EO, Aina OI, Kio F, Aluko $Y$ and Mosuro $\mathrm{O}$. The Influence of Socieconomic and Nutrtiona Status on menarche in Nigerian Schoolgirls. Nutr Health. 1997;11(3):185-95.

15. Ellis RWB. Age of Puberty in the Tropics. BMJ. 1950;1(4645):85-9.

16. Oduntan SO, Ayeni O, Kale OO. The Age at Menarche in Nigerian Girls. Ann. Hum Biol. 1976;3(3):269-74.

17. Kurdzielewicz M. Analysis of Selected Environmental and Biophysical Parameters during Menarche. Ann Acad Med Stetin. 2001;47:125-43.

18. Frisch R, Revelle R. Height and Weight at menarche and a Hypothesis of Critical body weight and Adolescent Events. Science.1970:169:397-9.

19. Simondon KB, Simon I, Simondon F. Nutritional status and age at menarche of Senegalese adolescents. Ann Hum Biol. 1997;24(6):521-32.

20. Akinyanju OA. A profile of Sickle Cell Disease in Nigeria. Ann NY Acad Sci. 1989:565:126-36.

21. Hilman R. Heamoglobinopathy. In: Hematology for Clinical Practice. $4^{\text {th }}$ Ed. McGraw Hill Companies. New York. 2005;80-5. 